$\begin{array}{lllllllllllllllll}\text { A C T A } & \text { C H E M I C A } & \text { S C A N D I N A V I C A } & \text { Z } & \text { (1 95 3) } & 969-973\end{array}$

\title{
Hydrolytic Degradation of Diheterolevulosan I and II Hexamethyl Ethers
}

\author{
B E N G T L I D B ERG a nd B Ö J E W I CKB ER G * \\ Institutionen för organisk kemi, Kungl. Tekniska Högskolan, Stockholm, Sweden
}

$\mathrm{O}_{\mathrm{o}}$

ur interest in the chemistry of fructose anhydrides originated from a study of crystallisation inhibitors in the beet sugar refining process. Apparently, however, they do not act as inhibitors in this process.

Three difructose anhydrides have been isolated from inulin hydrolysates, and a further two, diheterolevulosan $I$ and $I I^{1,2}$ have been obtained by the action of strong hydrochloric acid on fructose. (The field of difructose dianhydrides has been reviewed in more detail elsewhere ${ }^{3-5}$.) In the present paper improved methods are described for the methylation of the diheterolevulosan acetates, for the hydrolytic degradation of the hexamethyl ethers and the identification of the fructose trimethyl ethers formed.

By methylation of the diheterolevulosan hexaacetates with methyl sulphate and aqueous sodium hydroxide in acetone, rather unsatisfactory yields were obtained, probably due to the fact that incompletely methylated fractions are difficult to extract from the aqueous phase. Green, Myers and Grant ${ }^{6}$ recommended the use of solid sodium hydroxide in dry acetone, and by using dioxane, which gives no condensation products by the action of alkali instead of acetone, we have further improved the method, which, of course, is of general application.

The structure of diheterolevulosan I as a $1,2^{\prime}: 2,1^{\prime}$-di-D-fructopyranose dianhydride was elucidated by Schlubach and Behre ${ }^{1}$ by hydrolysis of the hexamethyl ether and isolation of D-fructose 3,4,5-trimethyl ether, which, however, was of doubtful purity. We have repeated these experiments as well as the preparation of D-fructose 3,4,5-trimethyl ether by the method of Irvine and Patterson ${ }^{7}$ and in both cases products of improved purity, $[\alpha]_{D}^{20}$ $-128^{\circ}$ (present investigation) compared with $-116^{\circ}$ (Irvine and Patterson) and $-70.5^{\circ}$ (Schlubach and Behre) were obtained. That the compounds were identical was established by means of paper chromatography and by conversion to the $p$-nitrophenyl osazones. The melting point reported in the literature ${ }^{8}$ for the osazone $\left(206-210^{\circ}\right)$ is considerably lower than that now obtained

* Svenska Sockerfabriks AB Research Fellow 1950-1953.

Acta Chem. Scand. 7 (1953) No. 6 
$\left(235-236^{\circ}\right)$, probably due to insufficient purification. However, the validity of Sohlubach and Behre's conclusions is confirmed.

During the course of our studies Wolfrom et al. ${ }^{9}$ showed by oxidative hydrolysis of the hexamethyl ether, that diheterolevulosan II is a D-fructopyranose $D$-fructofuranose $1.2^{\prime}: 2.1^{\prime}$-dianhydride. We arrived at the same structure by an independent course of reactions. On hydrolysis diheterolevulosan II hexamethyl ether yielded fructose 3,4,5-trimethyl ether and fructose 3,4,6-trimethyl ether, which could be easily separated and identified by partition chromatography. As the hexamethyl ether is resistant to hydrolysis and the fructose trimethyl ethers are rather sensitive to acids, it proved convenient to carry out an incomplete hydrolysis and separate the trimethyl ethers from unchanged starting material by partition between water and chloroform. The trimethyl ethers were oxidised with lead tetraacetate, the.resultant arabonolactones were purified by distillation and converted to the corresponding arabonamides by treatment with liquid ammonia. The yields of pure arabonamides were satisfactory, $75-80 \%$ and $38 \%$ calculated on the basis of fructose trimethyl ether and of diheterolevulosan II, respectively.

\section{EXPERIMENTAL}

Preparation of diheterolevulosan I and II. D-Fructose $(50 \mathrm{~g})$ was dissolved in cold $\left(0^{\circ}\right)$ concentrated hydrochloric acid $(d=1.19,200 \mathrm{ml})$ and left in the refrigerator $\left(0^{\circ}\right)$ for three days. The dark coloured solution was then filtered through asbestos wool; part of the hydrogen chloride was removed in vacuo and the solution was neutralized with lead carbonate, filtered and treated with hydrogen sulphide. The solution was then passed through a column of Amberlite IR 4B. The volume was made up to $400 \mathrm{ml}$ with water, and baker's yeast $(25 \mathrm{~g})$ in $200 \mathrm{ml} 0.9 \% \mathrm{NaH}_{2} \mathrm{PO}_{4}$ added. After standing overnight at $35^{\circ}$ the solution was filtered, treated with lead acetate and hydrogen sulphide and, after filtration, passed through columns of the Amberlite resins IR 120 and IR 4 B. Evaporation and drying with ethanol-benzene in vacuo afforded a thick syrup which was dissolved in a small volume of hot methanol. Crystalline material $(6 \mathrm{~g})$ immediately began to separate and was collected when crystallisation was complete. The methanolic mother liquours were poured into a large volume of acetone, whereby an amorphous material (13 g) was precipitated.

On paper chromatograms (solvent: $n$-butanol-ethanol-water $5: 1: 4$, upper layer) the crystalline fraction gave two spots, the $R_{F}$ values of which were less than that of fructose. They were detected with the following three reagents: Resorcinol-hydrochloric acid, silver nitrate followed by sodium hydroxide in ethanol and sodium periodate followed by Schiff's reagent.

The crystalline fraction was recrystallised by evaporating an aqueous solution to a strongly supersaturated syrup, which was diluted with methanol and left to crystallise. By following the separation chromatographically one of the compounds was obtained almost pure after a few recrystallisations. The substance $(3.4 \mathrm{~g})$ was dissolved in a warm mixture of pyridine $(70 \mathrm{ml})$ and acetic anhydride $(35 \mathrm{ml})$ and left overnight. The bulk of the solvent was removed by distillation under reduced pressure, the residue was taken up in chloroform and washed with dilute sulphuric acid, then with sodium bicarbonate solution and finally run through a short column of alumina. The acetate crystallised from methanol in needles, m.p. $168-9^{\circ *}$. $[a]_{D}^{20}-58^{\circ}$ (chloroform, $c=2$ ). Deacetylation of the pure acetate with catalytic amounts of sodium ethoxide in absolute ethanol yielded pure diheterolevulosan I. M.p. $270-3^{\circ}$. $[\alpha]_{\mathrm{D}}^{20}-44^{\circ}$ (water, $c=2$ ). Melting point determinations were difficult to reproduce owing to decomposition which appeared to proceed autocatalytically. The $R_{F}$-value on paper chromatograms was about half of that of fructose.

* All melting points uncorrected.

Acta Chem. Scand. 7 (1953) No. 6 
The second component which was enriched in the mother liquours could not be obtained in a pure state by recrystallisation. However, when the amorphous anhydride mixture mentioned above $(13 \mathrm{~g})$ was dissolved in methanol it yielded crystalline material (4.9 $\mathrm{g}$ ) which upon recrystallisation from pyridine-methanol gave chromatographically pure diheterolevulosan II (2.2 g). M.p. $255-6^{\circ},[\alpha]_{D}^{20}-40^{\circ}$ (water, $c=2$ ). The process could not be reproduced. On paper chromatograms diheterolevulosan II travels with a speed intermediate that of diheterolevulosan $I$ and fructose.

Acetylation of diheterolevulosan II in pyridine-acetic anhydride at room temperature gave an amorphous acetate which crystallised in needles from absolute ethanol on long standing at $0^{\circ}$. M.p. $121-2^{\circ},[\alpha]_{D}^{20}-41^{\circ}$ (chloroform, $c=2$ ) in good agreement with the values reported by Wolfrom et al. Later a sample of the crystalline acetate after standing in its ethanolic mother liquour was transformed to stout prisms which softened below $70^{\circ}$ on rapid heating and probably contained alcohol of crystallisation. When an airdry and obviously not quite homogenous sample was dried in vacuo at $95^{\circ}$ the loss of weight corresponded to 0.8 mole of ethanol pro mole acetate. When a sample of the prisms was allowed to stand slightly above room temperature in a small amount of ethanol overnight it was completely converted to the needle form.

Diheterolevulosan I hexamethyl ether. Dioxane $(35 \mathrm{ml})$ and mothyl sulphate $(1 \mathrm{ml})$ were added to diheterolevulosan I hexa-acetate $(1.7 \mathrm{~g})$ and powdered sodium hydroxide $(3.6 \mathrm{~g})$. The mixture was then heated to $70^{\circ}$ with vigorous stirring and methyl sulphate $(3.6 \mathrm{ml})$ added in $0.5 \mathrm{ml}$ portions over a period of 45 minutes. The mixture was heated for two hours and left at room temperature overnight. It was then filtered under suction care being taken to prevent cracking of the gelatinous filter cake which was then thoroughly washed with dry benzene. The combined filtrates were evaporated under reduced pressure and the resulting pale syrup dissolved in liquid ammonia $(4 \mathrm{ml})$. Potassium was added to produce a stable blue colour, and, after the ammonia had evaporated methyl iodide $(2 \mathrm{ml})$ was added. After standing overnight the mixture was heated to boiling for a short time, the unreacted methyl iodide was removed by distillation and the residue extracted with chloroform. The solution was filtered and the filtrate was run through a short column of alumina and then evaporated to dryness. The residue, on addition of light petroleum, crystallised in needles, m.p. $152-9^{\circ}$. The product was distilled $(0.7 \mathrm{~mm}$, bath temperature $210^{\circ}$ ) and the distillate recrystallised from chloroform-light petroleum. Yield $0.98 \mathrm{~g}$ or $80 \%$ of theory.

Twice recrystallised from acetone-isopropyl ether it formed fine needles, m.p. $160-1^{\circ}$, $[\alpha]_{D}^{20}-49^{\circ}$ (chloroform, $c=2$ ). A further crystallisation resulted in the formation of small prisms together with the needles. When the mixture was left overnight at room temperature in acetone-isopropyl ether only prisms remsined. On heating to $146-7^{\circ}$ they'melted to a liquid which then solidified and finally melted over a wide range (150$160^{\circ}$ ). The lowmelting form is probably identical with the $\alpha$ or $\beta$ modification reported by Sattler et al., m.p. $143-5^{\circ}$ and $145-7^{\circ}$. Efforts to regain the new highmelting form with a sharp melting point failed, the products obtained melting in the range $155-160^{\circ}$.

Hydrolysis of diheterolevulosan I hexamethyl ether. The hexamethyl ether (0.5 g) was dissolved in $1.5 N$ sulphuric acid $(10 \mathrm{ml})$ and the solution heated to $80^{\circ}$ for 18.5 hours. After neutralisation with barium carbonate and filtration the hydrolysate was extracted with chloroform $(4 \times 5 \mathrm{ml})$. The aqueous phase was evaporated to dryness under reduced pressure and the resulting syrup was dissolved in chloroform and run through a short column of alumina. The column was thoroughly washed and the chloroform solution eva. porated to a syrup $(0.3 \mathrm{~g})$ which was distilled. A distillate $(215 \mathrm{mg}),[a]_{\mathrm{D}}^{20}-125^{\circ}$ (after 15 minutes) and $-132^{\circ}$ (final value) (water, $c=2$ ), was obtained at $142-3^{\circ} / 0.42 \mathrm{~mm}$ bath temperature.

An authentic sample of fructose 3,4,5-trimethyl ether prepared according to Irvine and Patterson distilled under the same conditions and mutarotated slightly to the final value $[\alpha]_{\mathrm{D}}^{20}-128^{\circ}$ (water, $c=2$ ). 1

$p$-Nitrophenyl osazone of fructose 3,4,5-trimethyl ether. Fructose 3,4,5-trimethyl ether $(100 \mathrm{mg}), p$-nitrophenylhydrazin $(250 \mathrm{mg})$ and acetic acid $(1.5 \mathrm{ml})$ were mixed with water $(5 \mathrm{ml})$ and heated on a water bath for 45 minutes. The reaction mixture was diluted with water $(5 \mathrm{ml})$ and cooled. The crystalline precipitate was collected, washed with hot dilute acetic acid and dissolved in a small volume of chloroform. The solution was added to the

Acta Chem. Scand. 7 (1953) No. 6 
top of an alumina column $(1.8 \times 20 \mathrm{~cm})$ and the chromatogram developed with the same solvent. The chromatogram was very complicated, but from an orange coloured zone two fractions (50 mg, m.p. $235-6^{\circ}$ and $23 \mathrm{mg}, \mathrm{m} . \mathrm{p} .229-30^{\circ}$ ) were obtained which probably consisted of the desired osazone. This corresponds to $23 \%$ and $9 \%$ of theory. Analyqiis (main fraction): Found $\mathrm{CH}_{3} \mathrm{O}$, 18.1. Calc. for $\mathrm{C}_{18} \mathrm{H}_{17} \mathrm{O}_{5} \mathrm{~N}_{6}\left(\mathrm{OCH}_{3}\right)_{3}: \mathrm{CH}_{3} \mathrm{O}, 19.0 \%$. By this procedure fructose trimethyl ether from the hydrolysis of diheterolevulosan I hexamethyl ether gave the same osazone in about the same yield. M.p. 234-5 or in admixture with an authentic sample.

Diheterolevulosan. II hexamethyl ether. Methylation of diheterolevulosan II hexaacetate $(1.7 \mathrm{~g})$ as described for diheterolevulosan I hexamethyl ether (omitting the distillation) afforded prisms from acetone-isopropyl ether, m.p. 100-100.5,$[\alpha]_{\mathrm{D}}^{20}-21^{\circ}$ (chloroform, $c=2$ ). Yield $1.06 \mathrm{~g}$ or $86 \%$ of theory.

Hydrolysis of diheterolevulosan II hexamethyl ether. A preliminary experiment showed that hydrolysis of diheterolevulosan II hexamethyl ether in $N$ sulphuric acid reached half completion in about 20 hours at $80^{\circ}$. Paper chromatograms (solvent: benzene-ethanol $52: 9$, saturated with water) indicated the presence of fructose 3,4,5-trimethyl ether and fructose 3,4,6-trimethyl ether. $R_{F}$ values and colour reactions were identical with those of authentic materials. Spraying reagents were: Resorcinol-hydrochloric acid, aniline hydrogen phtalate and $p$-anisidin phosphate. There also were two fast-moving components, probably furan derivatives, which gave a yellow colour with the $p$-anisidin reagent even in the cold.

The hydrolysis was repeated using larger quantities of material (hexamethyl ether $(500 \mathrm{mg})$ in $N$ sulphuric acid $(10 \mathrm{ml}))$. The filtrate, after neutralisation of the hydrolysate with barium carbonate, was evaporated to $7 \mathrm{ml}$ volume and extracted with chloroform $(4 \times 1 \mathrm{ml})$. The chloroform extract was washed with $1 \mathrm{ml}$ water which was finally extrac. ted with chloroform $(2 \times 0.3 \mathrm{ml})$. On the addition of isopropyl ether to the combined and concentrated chloroform extracts unchanged hexamethyl ether $(246 \mathrm{mg}$, m.p. 99.5$\left.100.5^{\circ}\right)$ and an oil $(22 \mathrm{mg}$ ) were obtained. The oil was combined with the aqueous solutions.

After evaporation of the aqueous solution, the mixture of the fructose trimethyl ethers was separated on a hydrocellulose column $(2 \times 20 \mathrm{~cm})$ using benzene-ethanol $50: 4$, saturated with water, as solvent. The eluate was collected in $3 \mathrm{ml}$ fractions which were examined by paper chromatography.

Fractions $9-15$ were evaporated giving $27 \mathrm{mg}$ of an oil from which crystalline diheterolevulosan II hexamethyl ether $(8 \mathrm{mg}$ ) was recovered.

Fractions 16-21 yielded an oil $(108 \mathrm{mg})$ which contained the bulk of the fructose 3,4,6-trimethyl ether.

Fractions 22 and 23 contained small amounts of both methyl ethers and were discarded.

Fractions 24-32 yielded an oil $(77 \mathrm{mg})$ containing the fructose 3,4,5-trimethyl ether. D-Arabonamide 2,3,5-trimethyl ether from fructose 3,4,6-trimethyl ether. Authentic fructose 3,4,6-trimethyl ether, chromatographically pure, $[\alpha]_{\mathrm{D}}^{20}+21^{\circ}$ (chloroform, $c=2.1$ ) was prepared by hydrolysis of fully methylated inulin and subsequent chromatography on a cellulose column, followed by distillation.

The trimethyl ether $(120 \mathrm{mg})$ was dissolved in acetic acid $(2 \mathrm{ml})$ and water $(1 \mathrm{ml})$. The stoichiometric amount $(240 \mathrm{mg})$ of lead tetraacetate was added. After two hours at room temperature the solution gave a faint blue spot on potassium iodide-starch paper. Water $(1 \mathrm{ml})$ was added and the solution was then left overnight. After small amounts of lead dioxide had been removed by filtration the solution was saturated with hydrogen sulphide, and centrifuged. The clear solution was evaporated under reduced pressure and the residue distilled under water pump pressure (bath temperature $130-5^{\circ}$ ) for complete conversion of the arabonic acid derivative to the corresponding lactone. The distillate was dissolved in liquid ammonia which was then allowed to evaporate. The crystalline residue was dissolved in boiling acetone from which on cooling the amide crystallised in needles, m.p. 136 $-7^{\circ}$. More material was obtained from the mother liquors by addition of isopropyl ether, the total yield being $85 \mathrm{mg}$ or $75 \%$ of theory. After recrystallisation from acetone, the melting point was unchanged. $[\alpha]_{D}^{20}-13^{\circ}$ (water, $c=1.8$ ). The values reported for the corresponding $L$-derivative is $138^{\circ}$ and $[\alpha]_{\mathrm{D}}^{20}+18^{\circ}$ (water, $\left.c=1.3\right)^{10}$. 
On application of this procedure to the fructose 3,4,6-trimethyl ether from the hydrolysate there was obtained $47 \mathrm{mg}$ (overall yield $38 \%$ of theory) of the amide. M.p. 135.56.5 $5^{\circ}$ Recrystallised once from acetone-isopropyl ether it melted at $136-7^{\circ}$ alone or admixed with authentic substance.

D-Arabonamide 2,3,4-trimethyl ether from fructose 3,4,5-trimethyl ether. Prepared by the method described above for D-arabonamide 2,3,5-trimethyl ether, the lactone distilled at $150-60^{\circ}$ bath temperature under water pump pressure. The amide obtained from authentic fructose 3,4,5-trimethyl ether melted at $102.5-3^{\circ}$, $[\alpha]_{\mathrm{D}}^{20}-28^{\circ}$ (water, $c=1.5$ )

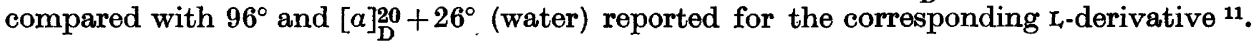
The yield was $80 \%$ of theory.

From the hydrolysate there was obtained $47 \mathrm{mg}$ (38 \% of theory) of the amide, m.p. $101-2^{\circ}$. Recrystallised once from acetone-isopropyl ether it melted at $102.5-3^{\circ}$, alone or admixed with authentic sample.

\section{SUMMARY}

Diheterolevulosan I and II hexamethyl ethers have been hydrolysed and the D-fructose 3,4,5- and 3,4,6-trimethyl ethers obtained characterised by oxidation with lead tetraacetate and subsequent conversion of the resultant arabonolactones by means of liquid ammonia, to the corresponding arabonamide trimethyl ethers.

The methylation procedure has been modified by using methyl sulphate and solid sodium hydroxide in dry dioxane.

\section{REFERENCES}

1. Schlubach, H. H., and Behre, C. Ann. 508 (1933) 16.

2. Wolfrom, M. L., and Blair, M. C. J. Am. Chem. Soc. 70 (1948) 2406.

3. McDonald, E. J. Advances in carbohydrate Chem. 2 (1946) 265.

4. Sattler, L., Zerban, F. W., Clark, G. L., Chia-Chen-Chu, Albon, N., Gross, D., and De Whalley, H. C. S. Ind. Eng. Chem. 44 (1952) 1127.

5. Wolfrom, M. L., Hilton, H. W., and Binkley, W. W. J. Am. Chem. Soc. 74 (1952) 2867.

6. Glen, W. L., Myers, G. S., and Grant, G. A. J. Chem. Soc. 19512568.

7. Irvine, J. C., and Patterson, Y. J. Chem. Soc. 121 (1922) 2146.

8. Sattler, L., and Zerban, F. W. Ind. Eng. Chem. 37 (1945) 1133.

9. Wolfrom, M. L., Binkley, W. W., Shilling, W. L., and Hilton, H. W. J. Am. Chem. Soc. 73 (1951) 3553.

10. Cunneen, J. I., and Smith, F. J. Chem. Soc. 19481154.

11. Humphreys, R. W., Pryde, J., and Waters, E. T. J. Chem. Soc. 19311302.

Received April 4, 1953.

Acta Chem. Scand. 7 (1953) No. 6 